\title{
COMMENTARY
}

\section{Interfacing the ICU with the general practitioner}

\author{
Armand RJ Girbes* and Albertus Beishuizen \\ See related research by Etesse et al., http://ccforum.com/content/14/3/R112
}

\begin{abstract}
For many reasons it is crucial that treating intensivists have (regular) contact with general practitioners (GPs). Information about the premorbid condition of the patient, their will and wishes, is of importance to be able to set appropriate treatment goals. The GP is the doctor who is responsible for the patient once discharged from the hospital. Additionally, the GP can play an important early role in the support of relatives, provided the GP is timely informed. This kind of communication should be organized in a structured way within the intensive care unit department.
\end{abstract}

Admission to the intensive care unit (ICU) is only part of the course that a patient makes during their illness. Intensive care is not a gatekeeper speciality and patients therefore generally have their first contact in a hospital with emergency physicians, surgeons, internists, cardiologists, and so forth.

After discharge from the ICU, most patients will return to the gatekeeper speciality - surgery, internal medicine, or the like. Following discharge from the hospital, patients will return to their homes and therefore the contact with their lifetime physician from their home situation, the general practitioner (GP), is of utmost importance. This is even more relevant when coordination of care from different specialists is required. The GP is also expected to have longstanding knowledge of the home situation of the patient. Whenever decisions in terms of end-of-life decisions have to be taken during ICU admission, the intensivist should be well informed. Not only is medical professional judgement important, but also the will and wishes of the patient. To gather all this information, the intensivist should contact doctors who have been involved in the treatment of the patient so far, including the GP, as well as the patient and relatives if

*Correspondence: arj.girbes@vumc.nl

Department of Intensive Care, VU University Medical Center Amsterdam, PO Box 7057, 1007 MB Amsterdam, The Netherlands possible. It should therefore be stressed as crucial that treating intensivists have (regular) contact with GPs.

Etesse and colleagues report in the present issue of Critical Care about the relationship between GPs and intensivists in a part of southeastern France [1]. The authors mailed an anonymous questionnaire to over 7,000 GPs in their region. The response rate was very low $(20 \%)$ and this will influence the results and conclusion. However, the results were devastating. Only one-half of the GPs rated their contact with the intensivist (on a scale from 1 to 100 ) at $>57$, and only $25 \%$ rated as $>77$. The conclusion that GPs are not very satisfied by communication with intensivists is therefore an understatement. To which extent the general dissatisfaction of GPs influences the results is not addressed in this French study. Data from The Netherlands suggest that overall professional satisfaction is worrisome, especially in the older GPs, and that 34\% of all GPs want to stop working as a GP before the age of 60 [2]. It is of note that this general dissatisfaction is in line with the specific finding of the authors.

The authors did not address whether the ICUs involved were using any organizational structure within the department for communication with the GPs. The same holds true for structural contact with all involved gatekeeper specialists. It should be understood that in cases of end-of-life decisions where the GP has previous good contact with the family and patient, and therefore the best knowledge of the premorbid situation, the GP should be contacted and consulted [3].

Some major changes in the position of the GP, however, have occurred over the past decades. The solo-working GP, working 7/7 days, has disappeared since most GPs nowadays work in a team. A significant proportion of GPs work part-time, so the old perception of the GP who knows all his patients from birth to death is outdated. In addition, GPs are not always easily reached in a timely fashion, which seriously hampers the communication process. Although we are not aware of any data, it is not unreasonable to assume that a significant proportion of patients in the ICU do not know their GP very well. In such circumstances it is unlikely that the GP can add to the information required to make important decisions in the ICU. The information from the intensive care 
department regarding admission to the ICU should undeniably be given in all cases, and should be timely.

The authors correctly point out the consequences of ICU admission of the patient for their family and loved ones. Symptoms of anxiety and depression are very common in the relatives of critically ill patients. Psychiatric illness (depression, anxiety disorders or complicated grief disorders) can occur in as much as $30 \%$ of relatives who were confronted with death in an ICU [4]. GPs can play an important role in this respect, provided that they are well and timely informed. Etesse and colleagues must be congratulated on their effort, especially since they distillate tangible advice from their data that can be easily implemented in a communication structure of intensive care - including systematic telephone calls to the GP on admission of the patient to the ICU, good communication with the family, and instant information for the GP at the moment of discharge from the ICU. In our view, the end-of-life decisions are to be made primarily by the intensivist and the team involved, using all available and relevant information [3].

\section{Abbreviations}

$\mathrm{GP}$, general practitioner; ICU, intensive care unit.

\section{Competing interests}

The authors declare that they have no competing interests.

Published: 30 June 2010

\section{References}

1. Etesse B, Jaber S, Mura T, Leone M, Constantin JM, Michelet P, Zoric L, Capdevila X, Malavielle F, Allaouchiche B, Fabbro Peray P, Lefrant JY: How the relationships between general practitioners and intensivists can be improved: the general practitioners' point of view. Crit Care 2010, 11:R112.

2. Van Ham I: Job satisfaction of the Dutch GP. PhD Thesis, Department of GP Medicine, State University of Groningen; 2006. [http://dissertations.ub.rug.nl/ faculties/medicine/2006/i.van.ham/]

3. Girbes ARJ: Dying at the end of your life. Intensive Care Med 2004, 30:2143-2144.

4. Beishuizen A, Girbes ARJ: Interfacing the ICU with the next of kin. In Organisation and Management of Intensive Care. Edited by Flaatten $\mathrm{H}$, Moreno R, Putensen C, Rhodes A. Berlin: MMW; 2010.

doi:10.1186/cc9066

Cite this article as: Girbes ARJ, Beishuizen A: Interfacing the ICU with the general practitioner. Critical Care 2010, 14:172 